\title{
PANORAMA DAS PUBLICAÇÕES SOBRE COMPRAS PÚBLICAS SUSTENTÁVEIS NO BRASIL ANTES E DEPOIS DA RIO+20
}

\author{
Ana Maria Olivo ${ }^{1}$ \\ Gilberto Matias Ruffato ${ }^{2}$ \\ leda Margarete Oro ${ }^{3}$ \\ Silvio Santos Junior ${ }^{4}$
}

\begin{abstract}
RESUMO
Buscar alternativas para reduzir os impactos ambientais oriundos das atividades produtivas são preocupações na sociedade moderna. Como parte importante desse processo, os governos de alguns países têm procurado mitigar estes impactos, utilizando como estratégia o seu poder de compras, com a aquisição de produtos e serviços que causem o menor dano ambiental possível. O objetivo deste artigo é analisar os avanços das pesquisas sobre Compras Públicas Sustentáveis (CPS), antes e depois da Conferência das Nações Unidas sobre Desenvolvimento Sustentável (Rio+20), realizada em 2012, no Brasil. Quanto aos procedimentos metodológicos, em relação à abordagem do problema é qualitativo. Quanto aos objetivos é uma pesquisa descritiva. Os procedimentos utilizados para a coleta e análise dos dados foram técnicas de bibliometria e análise de conteúdo. Inicialmente foi realizada uma leitura flutuante para explorar os artigos e posteriormente foram analisados conforme características propostas por Bardin (2010): Exaustividade: onde todos os elementos que correspondiam aos critérios incluídos foram considerados; Representatividade: a análise foi feita com uma amostra representativa; Homogeneidade: os critérios para as escolhas foram feitos com técnicas idênticas e; Pertinência: certificou-se de que os dados estavam adequados em relação às fontes de informação. Os achados da pesquisa demonstraram que o campo está em desenvolvimento, embora sob o ponto de vista acadêmico ainda não atingiu a maturidade, pois importantes aspectos relacionados às compras públicas sustentáveis ainda têm sido negligenciados, visto a importância que essa temática representa no atual contexto global.
\end{abstract}

\footnotetext{
${ }^{1}$ Mestre em Engenharia da Produção e aluna do Doutorado Acadêmico em Administração da Universidade do Oeste de Santa Catarina - UNOESC; Administradora da Universidade Federal da Fronteira Sul (UFFS), em Chapecó/SC (Brasil). Email: anamaria.olivo@hotmail.com Orcid id: https://orcid.org/0000-0002-8455-6027.
}

${ }^{2}$ Mestre em Administração Estratégica de Negócios pela Universidad Nacional de Misiones/Argentina. Diploma Revalidado pela Universidade Federal do Pampa (UNIPAMPA/RS). Administrador da Universidade Federal da Fronteira Sul (UFFS), em Chapecó/SC (Brasil). Email: gilbertomatias@gmail.com Orcid Id: https://orcid.org/0000-0002-6303-1707.

${ }^{3}$ Doutora em Ciências Contábeis e Administração pela Universidade Regional de Blumenau (FURB). Professora dos Cursos de Administração (Mestrado e Doutorado) Universidade do Oeste de Santa Catarina, Chapecó/SC (Brasil) E-mail: ieda.oro@unoesc.edu.br Orcid id: https://orcid.org/0000-00022239-531X.

${ }^{4}$ Doutor em Agronegócio pela Universidade Federal do Rio Grande do Sul (UFRGS). Professor dos Cursos de Administração (Mestrado e Doutorado) da Universidade do Oeste de Santa Catarina UNOESC, Santa Catarina, (Brasil). E-mail: silviosantos.junior@unoesc.edu.br Orcid id: https://orcid.org/0000-0002-4962-9905

R. gest. sust. ambient., Florianópolis, v. 10, n. 2, p. 2-24, jun. 2021. 
Palavras-chave: Compras Públicas Sustentáveis. Licitações Sustentáveis. Sustentabilidade.

\section{ABSTRACT}

Searching for alternatives to reduce the environmental impacts arising from productive activities are concerns in modern society. As an important part of this process, the governments of some countries have sought to mitigate these impacts, using their purchasing power as a strategy, with the purchase of products and services that cause the least possible environmental damage. The purpose of this article is to analyze the progress of research on Sustainable Public Procurement (CPS), before and after the United Nations Conference on Sustainable Development (Rio + 20), held in 2012, in Brazil. As for the methodological procedures, in relation to the approach to the problem, it is qualitative. As for the objectives, it is a descriptive research. The procedures used for data collection and analysis were bibliometrics and content analysis techniques. Initially, a floating reading was carried out to explore the articles and later they were analyzed according to characteristics proposed by Bardin (2010): Completeness: where all the elements that corresponded to the included criteria were considered; Representativeness: the analysis was carried out with a representative sample; Homogeneity: the criteria for the choices were made with identical techniques and; Relevance: made sure that the data were adequate in relation to the sources of information. The research findings showed that the field is in development, although under the academic point of view it has not yet reached maturity, as important aspects related to sustainable public procurement have still been neglected, given the importance that this theme represents in the current global context.

Keywords: Sustainable Public Procurement. Sustainable Bids. Sustainability.

\section{INTRODUÇÃO}

Uma parcela significativa dos impactos ambientais é resultante das atividades produtivas e os governos, que são potenciais consumidores de bens e serviços, têm o poder de influenciar positivamente, por meio de aquisições que tenham maior teor de sustentabilidade. Rodrigues et. al., (2018), destacam que a atuação conjunta do Poder Público e da comunidade local, oportunizam a produção e comercialização de produtos e serviços mais sustentáveis que possam melhorar a qualidade de vida das pessoas e manter o equilíbrio do meio ambiente. Uma forma de colocar ações de sustentabilidade em prática é por meio da criação de normas que insiram padrões para utilização e descarte dos produtos consumidos ou adquiridos pelos processos licitatórios (BIDERMAN et al., 2008).

As primeiras discussões a respeito da sustentabilidade nas compras públicas foram iniciadas na Agenda 21, durante a Conferência das Nações Unidas sobre Meio Ambiente e Desenvolvimento (Rio-92) e continuaram na Conferência das Nações

R. gest. sust. ambient., Florianópolis, v. 10, n. 2, p. 2-24, jun. 2021. 
Unidas sobre Desenvolvimento Sustentável (Rio+20). No intuito de reforçar o compromisso com a sustentabilidade, no mesmo mês em que ocorreu a Rio+20, o Brasil consolidou o Programa de Contratações Sustentáveis, por meio do Decreto Federal no 7.746/2012. Com essa iniciativa, a administração pública federal passou a priorizar a aquisição de produtos e serviços que causem menores danos ambientais, e que reduzam o consumo de água e de energia em seus processos. Com esse decreto, o governo brasileiro visou incentivar a economia regional, dando preferência aos materiais, tecnologias e matérias-primas de origem local (BRASIL, 2012).

No Brasil, em 2016, o Produto Interno Bruto (PIB) resultou em $R \$ 6,266$ trilhões (de reais), sendo que o governo desembolsou mais de 600 bilhões de reais na aquisição de bens e contratações de serviços (aproximadamente 10\% do PIB). Essas aquisições consistiram em materiais de consumo, tais como produtos alimentícios, materiais de expediente e limpeza, bens permanentes (móveis, equipamentos e utensílios), além dos serviços terceirizados de limpeza, manutenção, transporte, até a realização de grandes obras (IBGE, 2017; BRASIL - MPDG, 2017).

Diante disso, após ampla revisão da literatura percebeu-se que as pesquisas sobre compras públicas sustentáveis podem ainda não ter alcançado maior representatividade no Brasil após a Rio+20, que foi quando o Brasil consolidou o Decreto Federal ำ 7.746/2012. Por essa razão, nesse estudo pretende-se responder à seguinte pergunta: Como ocorreu a evolução das pesquisas sobre as Compras Públicas Sustentáveis no Brasil, antes e depois da Rio+20? O presente estudo tem como objetivo verificar os avanços das pesquisas sobre Compras Públicas Sustentáveis (CPS), antes e depois da Rio+20. Para o levantamento dos dados, foram feitas pesquisas em bases no Portal de Periódicos Capes e na Spell, no período de 2008 a 2017.

Este trabalho é composto por 5 seções, sendo que na 1 foram apresentados os aspectos introdutórios, na seção 2 é feita a revisão teórica do tema, na seção 3 são explicados os procedimentos metodológicos, na seção 4 é feita a análise e discussão dos resultados encontrados e na seção 5 as considerações finais.

\section{SUSTENTABILIDADE E COMPRAS PÚBLICAS}

Segundo o Relatório de Brundtland de 1985, o conceito de desenvolvimento sustentável, apresentado pela ONU, é aquele que satisfaz as necessidades

R. gest. sust. ambient., Florianópolis, v. 10, n. 2, p. 2-24, jun. 2021. 
presentes, sem comprometer a capacidade das gerações futuras de suprir suas próprias necessidades. No entanto, a sustentabilidade ainda permeia por um campo de diversas interpretações, atrelada a ecossistemas, mudanças de condições climáticas, controle da poluição, o que significa apenas uma parte do que normalmente lhes diz respeito. A interpretação de sustentabilidade está atrelada à mudança de atitudes e comportamentos para tornar as empresas sustentáveis e responsabilizá-las por seu futuro sustentável de forma contínua e não apenas incidentalmente (MILLAR; GITSHAM, 2013).

Elkington (1997) introduziu o conceito do Triple Bottom Line (TBL), por meio do qual destaca os três pilares da sustentabilidade: o ambiental, o econômico e o social (BLACKBURN, 2007). Os três pilares buscam o equilíbrio entre a eficiência econômica, a equidade social e preservação ambiental, importantes elementos para as organizações que desejam medir seu desempenho (ELKINGTON, 2001). Apesar disso, conflitos podem surgir quando são feitos esforços para equilibrar os aspectos ecológicos, econômicos e aspectos sociais. Não obstante, a resolução deles é parte essencial da integração e equilíbrio das três dimensões da sustentabilidade (HANSMANN et al., 2012).

Diversos eventos globais foram realizados para conscientizar as nações sobre a importância da sustentabilidade, conforme apresentados no Quadro 1.

Quadro 1 - Principais eventos globais sobre meio ambiente

\begin{tabular}{|c|c|c|c|}
\hline vento & Local & Discussões & Resultados \\
\hline $\begin{array}{l}1972 \text { - Conferência } \\
\text { Mundial sobre Homem } \\
\text { e o Meio Ambiente. }\end{array}$ & $\begin{array}{l}\text { Estocolmo- } \\
\text { Suécia. }\end{array}$ & $\begin{array}{l}\text { Crescimento populacional; } \\
\text { poluição atmosférica e uso } \\
\text { de recursos naturais. }\end{array}$ & $\begin{array}{l}\text { Declaração relacionada } \\
\text { à preservação e uso dos } \\
\text { recursos naturais. }\end{array}$ \\
\hline $\begin{array}{l}1992 \text { - Conferência das } \\
\text { Nações Unidas sobre o } \\
\text { Meio Ambiente e o } \\
\text { Desenvolvimento (Rio } \\
\text { 92). }\end{array}$ & $\begin{array}{c}\text { Rio de Janeiro - } \\
\text { Brasil }\end{array}$ & $\begin{array}{l}\text { Equilíbrio } \\
\text { desenvolvimento social e } \\
\text { econômico e e a } \\
\text { conservação e proteção do } \\
\text { ambiente. }\end{array}$ & $\begin{array}{l}\text { Agenda } 21 \text { - Programa } \\
\text { de ações para o } \\
\text { desenvolvimento } \\
\text { sustentável para o } \\
\text { século } 21 \text {, assinado por } \\
179 \text { países. }\end{array}$ \\
\hline $\begin{array}{l}2002 \text { - Conferência das } \\
\text { Nações Unidas sobre } \\
\text { Ambiente } \\
\text { Desenvolvimento } \\
\text { Sustentável (Rio +10) }\end{array}$ & $\begin{array}{l}\text { Joanesburgo - } \\
\text { África do Sul }\end{array}$ & $\begin{array}{l}\text { Revisão das metas } \\
\text { propostas pela Agenda } 21 .\end{array}$ & $\begin{array}{l}\text { Declaração } r \text { de } \\
\text { Joanesburgo sobre } \\
\text { Desenvolvimento } \\
\text { Sustentável: Das nossas } \\
\text { origens ao futuro. }\end{array}$ \\
\hline $\begin{array}{l}2012 \text { - Conferência das } \\
\text { Nações Unidas sobre } \\
\text { Desenvolvimento } \\
\text { Sustentável, a } \\
\text { Conferência Rio+20. }\end{array}$ & $\begin{array}{c}\text { Rio de Janeiro - } \\
\text { Brasil }\end{array}$ & $\begin{array}{l}\text { Metas para } \\
\text { sustentabilidade. }\end{array}$ & $\begin{array}{l}\text { Documento: O Futuro } \\
\text { que queremos. }\end{array}$ \\
\hline
\end{tabular}

R. gest. sust. ambient., Florianópolis, v. 10, n. 2, p. 2-24, jun. 2021. 


\begin{tabular}{|l|l|ll|l|}
\hline $\begin{array}{l}2015 \text { - Cúpula de } \\
\text { Desenvolvimento } \\
\text { Sustentável }\end{array}$ & Nova York - EUA & $\begin{array}{l}\text { Novos Objetivos de } \\
\text { Desenvolvimento } \\
\text { Sustentável. }\end{array}$ & $\begin{array}{l}\text { Agenda 2030 para } 0 \\
\text { Desenvolvimento } \\
\text { Sustentável. }\end{array}$ \\
\hline
\end{tabular}

Fonte: Elaborado pelos autores com base nos documentos das Conferências apresentadas pela ONU (1972 a 2015).

Esses eventos demonstram a importância de os governos adotarem a sustentabilidade como um princípio norteador das políticas públicas, de forma a integrar os pilares ambientais. Em busca desse equilíbrio, uma das estratégias adotadas pelos governos de alguns países é por meio do seu poder de compras, dando preferência à aquisição de produtos e serviços que causem o menor dano ambiental possível e que valorizem as economias locais, com a geração de emprego e renda. Na Rio-92 constavam ideias relacionadas às compras públicas sustentáveis apontadas pela Agenda 21 e que foram ratificadas na Rio+10, em 2002. Posteriormente, em 2012, na Rio+20, para dar o devido exemplo, os governos estabeleceram que as compras dos insumos para esse evento fossem baseadas em critérios de sustentabilidade: eficiência energética, madeira certificada e materiais reciclados. Essa iniciativa realizada pelo governo brasileiro foi por meio do Decreto Federal no 7.746/2012, quando ficou consolidado o Programa de Contratações Sustentáveis (RELATÓRIO RIO+20, 2012; BRASIL, 2012). A Quadro 2 apresenta algumas das diretrizes sugeridas no Art. 4 desse decreto.

Quadro 2 - Diretrizes do Decreto Federal 7.746/2012 e os Pilares da Sustentabilidade

\begin{tabular}{|l|l|}
\hline \multicolumn{1}{|c|}{ Pilar } & \multicolumn{1}{c|}{ Aspectos do decreto } \\
\hline Econômico & $\begin{array}{l}\text { Preferência para materiais, tecnologias e matérias-primas de origem local; } \\
\text { Maior vida útil e menor custo de manutenção do bem e da obra. }\end{array}$ \\
\hline Ambiental & $\begin{array}{l}\text { Menor impacto sobre recursos naturais como flora, fauna, ar, solo e água; } \\
\text { Maior eficiência na utilização de recursos naturais como água e energia; } \\
\text { Uso de inovações que reduzam a pressão sobre recursos naturais; } \\
\text { Origem ambientalmente regular dos recursos naturais utilizados nos bens, serviços } \\
\text { e obras. }\end{array}$ \\
\hline Social & Maior geração de empregos, preferencialmente com mão de obra local. \\
\hline
\end{tabular}
Fonte: Brasil, 2012.

Conforme apresentado no Quadro 2, as diretrizes propostas nesse decreto revisitam os três pilares da sustentabilidade: econômico, ambiental e social. Destacase que os gastos públicos com compras podem representar entre 15\% e 30\% do PIB (Produto Interno Bruto) de um determinado país (IBGE, 2017; MPDG, 2017). Com isso, percebe-se que o poder de compra governamental é significativo. As compras públicas podem ser vistas por um lado como um ato meramente rotineiro, com função

R. gest. sust. ambient., Florianópolis, v. 10, n. 2, p. 2-24, jun. 2021. 
precípua de manter a sua cadeia de suprimentos, por outro "podem ser revestidas de critérios e mecanismos que as qualifiquem como um instrumento estratégico de políticas públicas" (NONATO, 2015, p.14).

Para assumirem o seu papel no contexto da sustentabilidade, diversos órgãos públicos, principalmente a partir de 2012, passaram a aderir às compras sustentáveis. Essa ação vem desempenhando papel fundamental na implementação das políticas públicas, no fomento às inovações tecnológicas, na transparência e controle social, mobilizando governo e iniciativa privada com ações que impactam em toda a sociedade.

No contexto das pesquisas sobre compras públicas sustentáveis, Castro, Silva e Lopes (2014) investigaram as contratações sustentáveis na administração pública brasileira no Poder Executivo federal. O estudo revelou que mais da metade dos órgãos do Poder Executivo federal tem participação inexpressiva nesse processo.

Lavor e Turatti, (2018), destacam que a regulamentação jurídica sobre as contratações públicas sustentáveis é ampla e dotada de complexidade. No entanto, para que as efetivas mudanças nas contratações públicas sejam efetivas é importante que os gestores públicos estabeleçam requisitos de julgamento das propostas com base em critérios ambientais e não somente no menor preço, desde que atendam ao interesse público.

Do Amaral Motta e Oliveira (2015), estudaram os desafios na participação de micro e pequenas empresas do município de São Mateus/ES e identificaram que o maior desafio das MPEs é a falta de informação sobre o processo licitatório, que vai desde a divulgação até ao levantamento da documentação necessária. O estudo revelou, também, que há a necessidade de se capacitar as empresas locais para que participem e obtenham resultados positivos nos certames de compras públicas sustentáveis.

Castro et. al., (2014) fizeram um estudo em Instituições Federais de Ensino Superior na Região Sul do Brasil e verificaram que a indução de critérios sustentáveis para as licitações requer não apenas normas, mas capacitação dos administradores para que a adoção dos requisitos seja efetiva. Castro et al. (2013) estudaram as licitações públicas sustentáveis em um Ministério do Brasil e não encontraram instituição pública oficial ou instituição credenciada para certificar as exigências

R. gest. sust. ambient., Florianópolis, v. 10, n. 2, p. 2-24, jun. 2021. 
contidas nos instrumentos convocatórios. Esta pesquisa reforçou a tendência do Brasil em regulamentar as compras públicas sustentáveis.

Couto e Coelho (2015), ao investigarem os fatores críticos no comportamento do gestor público responsável por compras sustentáveis e identificaram os fatores críticos que determinam o processo decisório de compra sustentável. Também identificaram diferenças relacionadas com o contexto de compra envolvido, em especial naquelas que envolvem preço, determinações da legislação e tempo gasto nas especificações dos produtos.

De Souza e Pfitscher (2013) estudaram a gestão e sustentabilidade ambiental em um órgão público do Estado de Santa Catarina e identificaram que o órgão em estudo estava em um nível regular de desempenho ambiental no percentual de $49,32 \%$. Esse resultado indicou que as práticas ambientais aplicadas estão mais destinadas a atender a legislação acerca da gestão e sustentabilidade ambiental.

Campagnini et al. (2014), investigaram a inclusão de práticas ambientais nas auditorias realizadas no âmbito de uma Instituição Federal de Educação. Os resultaram demonstraram que em relação aos controles ambientais, por força de lei, as instituições públicas federais têm a obrigatoriedade de implementarem o plano de logística sustentável (PLS) e divulgá-lo no site institucional. Diante da ausência de controles e auditorias ambientais evidenciadas, foi elaborado um rol contendo os principais fatores passíveis de acompanhamento na realização de auditorias ambientais em instituições públicas de educação.

Oliveira e Santos (2015), procuraram compreender como o Estado tem contribuído para o desenvolvimento sustentável a partir de seu poder de compra. Verificaram que as preocupações se limitam a questões ambientais e a dimensão social e que os avanços, embora tímidos, fortalecem modelos organizacionais não centrados na maximização do lucro, voltados a inclusão social, a justiça distributiva, ao equilíbrio ambiental e ao bem viver coletivo.

Santos et al. (2014) avaliaram a inserção de alimentos orgânicos na alimentação escolar, nos municípios integrantes dos territórios rurais do Rio Grande do Sul. O estudo identificou a necessidade da atuação intersetorial para desenvolver a produção orgânica, assim como estimular o consumo destes alimentos no ambiente escolar.

R. gest. sust. ambient., Florianópolis, v. 10, n. 2, p. 2-24, jun. 2021. 
Santos e Cândido (2014) analisaram como a formação de associação cooperativa fortaleceu os agricultores familiares do agreste da Paraíba, de modo que a associação apresentou resultados positivos e foi incluída no Programa de Aquisição de Alimentos (PAA). Nessa mesma linha de estudo, Sousa et al. (2015) realizaram um estudo sobre cardápios e sustentabilidade, sobre as diretrizes do Programa Nacional de Alimentação Escolar, de forma a refletir sobre a elaboração do cardápio instituído nas diretrizes de execução do Programa, com ênfase nos elementos que podem indicar a alimentação escolar como promotora de sistemas alimentares ecológicos e de desenvolvimento local sustentável. Concluíram que a gestão da compra e da logística, assim como o apoio governamental e o controle social por parte da comunidade escolar são elementos fundamentais para que os cardápios escolares dialoguem com a sustentabilidade.

Saraiva et al. (2013), pesquisaram o panorama da compra de alimentos da agricultura familiar para o Programa Nacional de Alimentação Escolar. Constataram que cerca da metade dos municípios brasileiros $(47,4 \%)$ adquiriram alimentos da agricultura familiar para a alimentação escolar e o percentual de compras foi, em média de 22,7\%, em 2010. A inviabilidade de fornecimento regular e constante, além de outros limites apresentados pelos municípios se destacaram como justificativas para o não atendimento dos $30 \%$ estabelecidos na lei.

Esses são alguns exemplos do que tem sido pesquisado no campo das compras públicas sustentáveis. Diante do exposto, a seção 3 apresenta os procedimentos metodológicos para verificar os avanços das pesquisas sobre Compras Públicas Sustentáveis (CPS), antes e após a Rio+20.

\section{PROCEDIMENTOS METODOLÓGICOS}

A caracterização dessa pesquisa, no que se refere à abordagem do problema, é qualitativa. Quanto aos objetivos, é classificada como descritiva. A pesquisa descritiva visa descrever as características de determinadas populações ou fenômenos (GIL, 2008). Em relação aos procedimentos para a coleta e análise dos dados, foram utilizadas técnicas de bibliometria e análise de conteúdo. "A Bibliometria é o estudo dos aspectos quantitativos da produção, disseminação e uso da informação registrada" (MACIAS-CHAPULA, 1998, p. 134). Desta forma, a revisão bibliométrica

R. gest. sust. ambient., Florianópolis, v. 10, n. 2, p. 2-24, jun. 2021. 
possibilitou traçar o panorama das publicações sobre CPS no Brasil, antes e após a realização da Rio +20 .

Concomitante às técnicas de bibliometria, foram utilizadas técnicas de análise de conteúdo. A análise de conteúdo se refere a um conjunto de técnicas de análise das comunicações, por meio da utilização de procedimentos sistemáticos e objetivos para descrever o conteúdo das mensagens, que pode ser feita em entrevistas, documentos ou relatórios (BARDIN, 2010). As fases de análise de conteúdo propostas por Bardin (2010) são: a pré-análise, a exploração do material e o tratamento dos resultados, inferência e interpretação. Ainda na pré-análise, realizou-se previamente a busca e classificação dos artigos por meio de técnicas de bibliometria.

Para explorar os artigos foi realizada a leitura flutuante, que consiste em tomar contato com o material, de forma a conhecer o seu conteúdo (MINAYO, 2007) e posteriormente eles foram submetidos às análises, conforme características propostas por Bardin (2010): Exaustividade - todos os elementos que correspondam aos critérios incluídos devem ser considerados; Representatividade - fazer análise sobre uma amostra que seja representativa; Homogeneidade - os critérios para as escolhas realizadas devem ser feitos por técnicas idênticas e; Pertinência - os dados precisam estar adequados no que se referem à fonte de informação. Dessa forma, a união de técnicas de bibliometria e de análise de conteúdo permitiu responder à seguinte pergunta de pesquisa: Como ocorreu a evolução das pesquisas sobre as Compras Púbicas Sustentáveis no Brasil, antes e depois da Rio+20?

\subsection{Delimitação do escopo e processo de coleta e análise dos dados}

Para delinear o panorama das publicações sobre CPS antes e após a Rio+20, na primeira etapa foram feitas buscas dos artigos (revisados por pares) na base de Periódicos da Capes e na Spell, publicados no período de 2008 a 2017. Este período contempla cinco anos de distanciamento, para mais e para menos, do evento de referência (Rio +20). Foram utilizados os termos: contratações públicas sustentáveis; licitações sustentáveis; compras sustentáveis; compras públicas sustentáveis; aquisições sustentáveis e aquisições públicas sustentáveis. Como forma de sistematização do processo, desde a coleta até a análise dos dados, o Quadro 3 apresenta as etapas que foram realizadas.

R. gest. sust. ambient., Florianópolis, v. 10, n. 2, p. 2-24, jun. 2021. 
Quadro 3 - Etapas para realização do estudo

\begin{tabular}{|c|c|}
\hline ETAPAS & PROCEDIMENTOS \\
\hline $\begin{array}{l}\text { Operacionalização } \\
\text { da pesquisa }\end{array}$ & $\begin{array}{l}\text { Escolha das bases científicas e periódicos; } \\
\text { Delimitação dos termos de busca. }\end{array}$ \\
\hline $\begin{array}{l}\text { Procedimentos de } \\
\text { busca (filtros) }\end{array}$ & 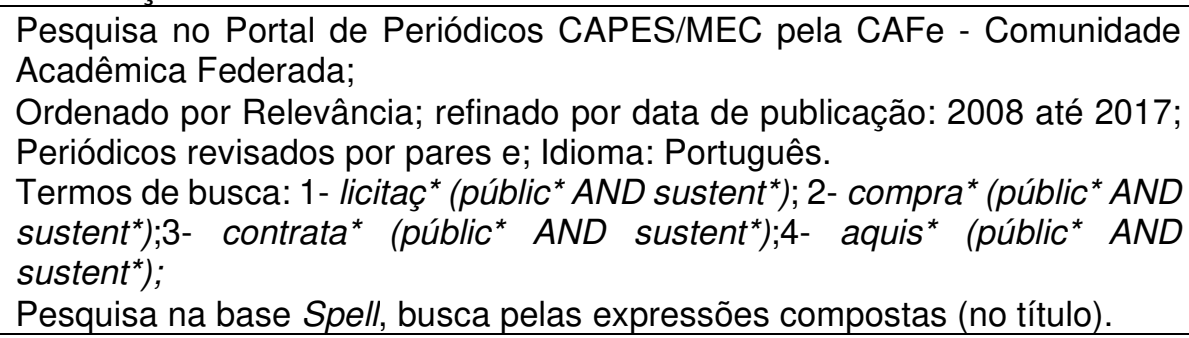 \\
\hline $\begin{array}{l}\text { Procedimentos de } \\
\text { seleção (Banco de } \\
\text { Dados) }\end{array}$ & $\begin{array}{l}\text { Download das referências- software JabRef;Download das referências- } \\
\text { criação de planilhas eletrônicas no Excel® para auxiliar na organização dos } \\
\text { dados. }\end{array}$ \\
\hline $\begin{array}{l}\text { Adequação e } \\
\text { organização dos } \\
\text { dados }\end{array}$ & $\begin{array}{l}\text { Eliminação dos artigos duplicados; } \\
\text { Busca de artigos completos em pdf. }\end{array}$ \\
\hline $\begin{array}{l}\text { Análise da produção } \\
\text { científica }\end{array}$ & $\begin{array}{l}\text { Análise do volume de publicações e tendências temporais; } \\
\text { Análise dos periódicos; } \\
\text { Análise das metodologias mais aplicadas nos estudos; } \\
\text { Análise de conteúdo dos artigos selecionados; } \\
\text { Descrição do panorama das pesquisas, estudo das relações e tendências. }\end{array}$ \\
\hline
\end{tabular}

Fonte: Os autores

No total foram encontrados 177 artigos. Destes, na primeira análise foram eliminados 137, por não se tratar do assunto pesquisado ou por estarem repetidos nas bases, resultando em 39 artigos válidos.

\subsection{Informações complementares: estudos bibliométricos sobre compras públicas sustentáveis}

Para verificação da validade da amostra, uma vez que o número de artigos encontrados foi considerado pequeno, recorreu-se a outras bases, de forma a buscar uma maior confiabilidade. Foram feitas consultas no Google Scholar® (em 27/1/2018), para simples verificação do universo de publicações existentes sobre a temática estudada. Desta busca, dois artigos bibliométricos relevantes foram encontrados, e que apresentam número de amostras semelhantes.

O artigo de Rosset e Finger (2017), intitulado: Compras públicas sustentáveis: uma revisão sistemática da pesquisa brasileira teve como objetivo fazer uma análise da produção científica em compras públicas e o foco dado para as compras sustentáveis na área. O período de pesquisa foi de 2004 a 2015, sendo analisados 23 artigos. Segundo os autores há uma identidade própria da produção acadêmica brasileira em compras públicas, com destaque para os temas "Compras Públicas

R. gest. sust. ambient., Florianópolis, v. 10, n. 2, p. 2-24, jun. 2021. 
Sustentáveis" e "Eficiência nas Compras Públicas" e constaram que a produção científica nessa área ainda é escassa.

O artigo de Júnior, De Azeredo e Costa (2014), intitulado: Compras Públicas Sustentáveis: Um Mapeamento da Produção científica através da Bibliometria teve como objetivo apresentar bibliometria no âmbito do tema compras públicas sustentáveis. Os pesquisadores analisaram artigos publicados no período entre 2000 a 2014, onde analisaram 30 artigos. Os autores constataram uma evolução significativa das publicações nessas duas bases a partir de 2010, ano da publicação da Instrução Normativa oㅜ 1, de 19 de janeiro de 2010, da Secretaria de Logística e Tecnologia da Informação do Ministério do Planejamento, Orçamento e Gestão (IN/SLTI/MPOG/2010), que dispõe sobre critérios de sustentabilidade ambiental na aquisição de bens, contratos de serviços ou obras pela Administração Pública Federal (BRASIL, MPOG, 2017).

No estudo bibliométrico de Rosset e Finger (2017) ficou em 23 artigos e no estudo de Júnior, De Azeredo e Costa (2014) restaram 30 artigos a serem analisados. $\mathrm{Na}$ presente pesquisa resultaram 39 artigos para análise. Com isso, se deduz que o número de reduzido de amostra segue tendência natural na temática de compras públicas sustentáveis, visto que ainda são poucos estudos realizados com essa temática. Posterior a essa consulta, procedeu-se à análise e discussões dos resultados encontrados nos 39 artigos selecionados para este estudo, conforme apresentados na seção seguinte.

\section{ANÁLISE E DISCUSSÕES DOS RESULTADOS}

A temática sobre compras públicas sustentáveis parece ser de interesse científico recente. A Figura 1 apresenta a distribuição dos artigos por ano de publicação.

Figura 1 - Distribuição de Artigos por ano de publicação

R. gest. sust. ambient., Florianópolis, v. 10, n. 2, p. 2-24, jun. 2021. 


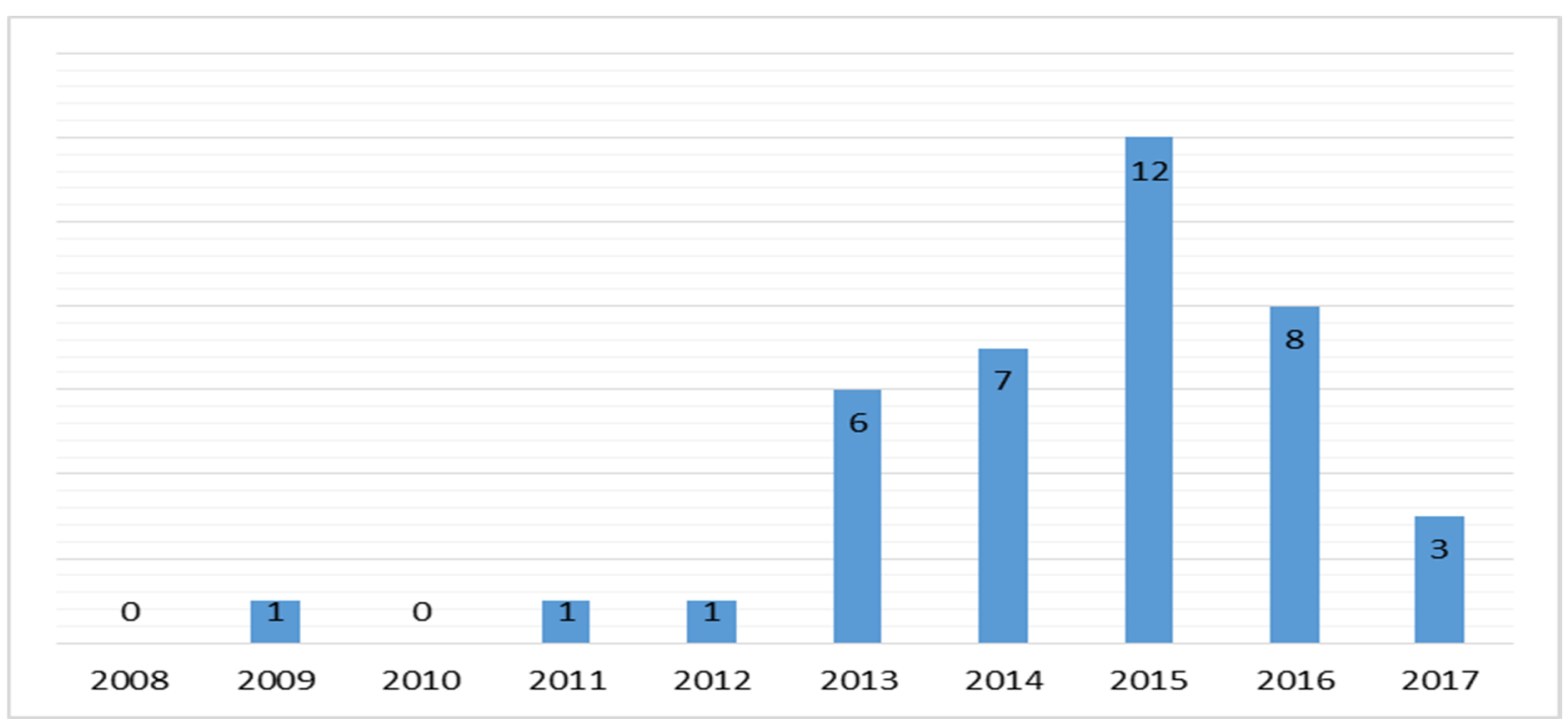

Fonte: Os autores

Observa-se na Figura 1, antes de 2012 foram publicados apenas dois artigos relacionados às compras públicas sustentáveis. A partir de 2012, ano do Decreto Federal oํ 7.746/2012, as instituições de pesquisa começam a se dedicar à temática com crescente interesse, sendo 2015 o ano com maior número de publicações e aparente ponto de inflexão da tendência. As causas do decréscimo do interesse acadêmico, demonstrada em 2016 e, mais acentuadamente em 2017, podem advir das crises institucionais que vem ocorrendo em anos recentes no Brasil, e/ou da aparente diminuição da importância que as políticas públicas mundiais vêm dando à questão ambiental. A sustentação deste último argumento, entretanto, não é objeto deste estudo e carece de investigação mais profunda.

Após o aparente ponto de inflexão das publicações ocorrido no ano de 2015, nos anos 2016 e 2017 em que houve o decréscimo, constataram-se que continuam com as mesmas características das publicações de 2015 e anteriores sendo, a maioria com amostras pequenas variando entre um e 42. No entanto, ela são de cunho exploratório e com dificuldades de generalização, o que não nos dá condições de afirmar que o campo está maduro e ou consolidado.

Os artigos com as maiores amostras do período estudado, entre os anos 2008 e 2017, apenas quatro utilizaram coletas de dados com amostras acima de 40 indivíduos. O primeiro estudo com o maior tamanho de amostra utilizou informações de 894 participantes alunos e servidores de uma instituição do estado do Ceará; o segundo estudo com amostra de 102 municípios de um estado brasileiro, analisando a aquisição de merenda escolar da agricultura familiar; o terceiro estudo analisou 89

R. gest. sust. ambient., Florianópolis, v. 10, n. 2, p. 2-24, jun. 2021. 
MPE's de um município do estado do Espírito Santo; o quarto estudo com amostra de 42 indivíduos contemplou 14 municípios do estado do Pará; o quinto estudo, do ano de 2014, utilizou informações de 12 ministérios do governo brasileiro, de um total de 26 , em que resultou que mais da metade deles faziam compras inexpressivas na área do estudo e, por último, o sexto estudo utilizou informações 12 Secretarias do Estado de São Paulo para investigar a aquisição de um produto específico, madeira de origem amazônica.

A Tabela 1 apresenta a distribuição dos artigos selecionados por revista e por instituição publicadora.

Tabela 1 - Distribuição dos artigos

\begin{tabular}{|c|c|c|c|c|}
\hline Revista & Qualis & $\begin{array}{c}\text { Instituição } \\
\text { Publicadora }\end{array}$ & Cidade/País & $\begin{array}{c}\mathrm{N} . \\
\text { Artigos }\end{array}$ \\
\hline $\begin{array}{l}\text { Revista de Gestão Ambiental e } \\
\text { Sustentabilidade }\end{array}$ & B2 & $\begin{array}{l}\text { Universidade Nove de Julho- } \\
\text { UNINOVE }\end{array}$ & São Paulo/SP & 5 \\
\hline Revista de Administração Pública & A2 & $\begin{array}{l}\text { Fundação Getúlio Vargas- } \\
\text { FGV }\end{array}$ & $\begin{array}{c}\text { Rio de } \\
\text { Janeiro/RJ }\end{array}$ & 4 \\
\hline Revista Ciência \& Saúde Coletiva & B1 & $\begin{array}{l}\text { Associação Brasileira de } \\
\text { Pós-Graduação em Saúde } \\
\text { Coletiva }\end{array}$ & $\begin{array}{l}\text { Rio de } \\
\text { Janeiro/RJ }\end{array}$ & 3 \\
\hline $\begin{array}{l}\text { Revista Metropolitana } \\
\text { Sustentabilidade }\end{array}$ & B3 & $\begin{array}{l}\text { Faculdades Metropolitanas } \\
\text { Unidas }\end{array}$ & São Paulo/SP & 3 \\
\hline $\begin{array}{lll}\text { Revista } & \text { Eletrônica } & \text { de } \\
\text { Administração - READ } & \end{array}$ & B1 & $\begin{array}{l}\text { Universidade Federal do Rio } \\
\text { Grande do Sul }\end{array}$ & $\begin{array}{c}\text { Porto } \\
\text { Alegre/RS }\end{array}$ & 3 \\
\hline $\begin{array}{l}\text { Revista Inovação, Projetos e } \\
\text { Tecnologias- IPTEC }\end{array}$ & B3 & $\begin{array}{l}\text { Universidade Nove de Julho- } \\
\text { UNINOVE }\end{array}$ & São Paulo/SP & 2 \\
\hline Revista de Administração - FACES & B2 & Universidade FUMEC/FACE & $\begin{array}{c}\text { Belo } \\
\text { Horizonte/MG }\end{array}$ & 2 \\
\hline Revista HOLOS & B1 & $\begin{array}{lcr}\text { Instituto } & \text { Federal } & \text { de } \\
\text { Educação } & \text { Ciência } & \text { e } \\
\text { Tecnologia } & & \end{array}$ & Natal/RN & 1 \\
\hline $\begin{array}{l}\text { Revista de Administração de } \\
\text { Empresas - RAE }\end{array}$ & A2 & Fundação Getúlio Vargas & $\begin{array}{c}\text { Rio de } \\
\text { Janeiro/RJ }\end{array}$ & 1 \\
\hline Revista FATEC Zona Sul - REFAS & B3 & $\begin{array}{l}\text { Faculdade de Tecnologia da } \\
\text { Zona Sul }\end{array}$ & São Paulo/SP & 1 \\
\hline Revista Ambiente Contábil & B3 & $\begin{array}{l}\text { Universidade Federal do Rio } \\
\text { Grande do Norte }\end{array}$ & Natal/RN & 1 \\
\hline $\begin{array}{l}\text { Revista da Universidade Vale do } \\
\text { Rio Verde }\end{array}$ & B1 & $\begin{array}{l}\text { Universidade Vale do Rio } \\
\text { Verde }\end{array}$ & $\begin{array}{c}\text { Três } \\
\text { Corações/MG }\end{array}$ & 1 \\
\hline $\begin{array}{lll}\text { Revista de } & \text { Contabilidade } & \text { e } \\
\text { Controladoria } & & \end{array}$ & B3 & $\begin{array}{l}\text { Universidade Federal do } \\
\text { Paraná }\end{array}$ & Curitiba/PR & 1 \\
\hline Revista de Nutrição & B2 & $\begin{array}{l}\text { Pontifícia Universidade } \\
\text { Católica de Campinas }\end{array}$ & Campinas/SP & 1 \\
\hline $\begin{array}{l}\text { Revista Eventos Pedagógicos } \\
\text { REP's }\end{array}$ & $\begin{array}{l}\text { B1 a } \\
\text { B4 }\end{array}$ & $\begin{array}{l}\text { Universidade do Estado de } \\
\text { Mato Grosso }\end{array}$ & Sinop/MT & 1 \\
\hline Liinc em Revista & B1 & $\begin{array}{l}\text { Universidade Federal do Rio } \\
\text { de Janeiro e IBICT }\end{array}$ & & 1 \\
\hline Revista Derecho \& Sociedad & - & $\begin{array}{l}\text { Pontifícia Universidade } \\
\text { Católica do Peru }\end{array}$ & $\begin{array}{l}\text { San Miguel } \\
\text { Lima/ Peru }\end{array}$ & 1 \\
\hline
\end{tabular}

R. gest. sust. ambient., Florianópolis, v. 10, n. 2, p. 2-24, jun. 2021. 
Revista Conpedi Law Review

Revista Contabilidade e Negócios

Revista Ciência da Administração RCA

Revista de Administração,

Contabilidade e Economia- Race

Revista de Administração,

Contabilidade e Economia da

Fundace - RACEF

Revista Amazônia, Organizações e

Sustentabilidade

Revista do Serviço Público
B5

Conselho Nacional de Pesquisa e Pós-Graduação em Direito (CONPEDI)

$\begin{array}{llll}\text { B2 Pontifícia Universidade San Miguel } & \text { Latora } \\ \text { Cima/ Peru } & 1 \\ \text { B1 Universidade Federal de } & \begin{array}{l}\text { Elorianópolis/S } \\ \text { Santa Catarina }\end{array} & 1\end{array}$

B3 Universidade do Oeste de Joaçaba/SC 1

Santa Catarina

B3 Fundação para Pesquisa e $\quad$ Ribeirão 1

Desenvolvimento Preto/SP

Administração,

Contabilidade e Economia

B3 e Universidade da Amazônia

B4
Belém/PA $\quad 1$

1

39

Fonte: Elaborado pelos autores

Total

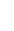

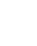

(1)

1

(1)

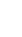

(39

As principais revistas que publicaram artigos sobre compras públicas sustentáveis foram a Revista de Gestão Ambiental e Sustentabilidade da UNINOVE (5 artigos), seguida da Revista de Administração Pública da FGV (4) e Revista Ciência \& Saúde Coletiva da Associação Brasileira de Pós-Graduação em Saúde Coletiva, Revista Metropolitana de Sustentabilidade das Faculdades Metropolitanas e Revista Eletrônica de Administração - READ (com 3 artigos cada), com 38,5\% da produção sobre o tema.

Os resultados demonstraram que a temática a respeito de compras públicas sustentáveis é interdisciplinar, perpassa tanto as áreas das Ciências Sociais e Aplicadas, como das Ciências da Saúde, Ciências Biológicas, dentre outras, uma vez que a sustentabilidade engloba o TBL de Elkington (1997), com os pilares econômico, social e ambiental.

O desenho e metodologias de pesquisa abordados nos artigos são apresentados na Tabela 2.

Tabela 2- Desenho e metodologia da pesquisa dos artigos de 2008 a 2017

\begin{tabular}{lcccc}
\hline Tipo de pesquisa & Exploratória & Descritiva & $\begin{array}{c}\text { Exploratória e } \\
\text { descritiva } \\
7\end{array}$ & $\begin{array}{c}\text { Não espec./ } \\
\text { outros } \\
6 \\
\text { (ensaios) }\end{array}$ \\
\hline Dimensão do tempo & 16 & 10 & Outros & $\begin{array}{c}\text { Não } \\
\text { espec./outros } \\
6\end{array}$ \\
\hline Amostragem & Transversal & Longitudinal & $\begin{array}{c}1 \text { (estudo } \\
\text { bibliométrico) }\end{array}$ & Não especificado ou outros \\
& Probabilística & $\begin{array}{c}\text { Não } \\
\text { probabilística }\end{array}$ & Nán
\end{tabular}

R. gest. sust. ambient., Florianópolis, v. 10, n. 2, p. 2-24, jun. 2021. 


\begin{tabular}{|c|c|c|c|c|}
\hline & 32 & 1 & & 6 \\
\hline \multirow[b]{2}{*}{ Tipo de pesquisa } & Qualitativas & Quantitativas & Qualitativas e & $\begin{array}{c}\text { Não } \\
\text { Naficano }\end{array}$ \\
\hline & 22 & 6 & $\begin{array}{c}\text { quantitativas } \\
4\end{array}$ & $\begin{array}{c}\text { especificado } \\
6 \\
\text { (ensaios) }\end{array}$ \\
\hline \multirow{2}{*}{$\begin{array}{l}\text { Técnicas de coleta de } \\
\text { dados }\end{array}$} & Bibliográfica/ & Entrevistas & Questionários & Outras \\
\hline & 10 & 20 & 9 & 0 \\
\hline Técnicas de análise & $\begin{array}{c}\text { Análise de Co } \\
30\end{array}$ & do/Documental & \multicolumn{2}{|c|}{ Análises Estatísticas } \\
\hline
\end{tabular}

Fonte: Dados da pesquisa.

De acordo como a Tabela 2, predominaram estudos exploratórios em 16 artigos, 10 foram descritivos, sete combinaram abordagens exploratórias e descritivas e seis foram ensaios teóricos. Os estudos transversais predominaram em 32 artigos. Constatou-se que foi realizado estudo longitudinal e seis ensaios que normalmente são transversais. Com relação aos tipos de pesquisa, 22 foram qualitativos, seis combinaram os métodos quantitativos e qualitativos e 6 eram ensaios teóricos.

Em relação às técnicas para coleta de dados, em 20 artigos foram realizadas entrevistas, em nove utilizaram-se questionários (embora alguns utilizaram de bibliografias e documentos para complementar a coleta) e em 10 recorreu-se às bibliografias e documentos. As técnicas de análise de conteúdo e documentais foram as mais utilizadas.

Com relação ao tamanho das amostras, dos 20 artigos que utilizaram a entrevista como fonte de coleta, três fizeram a entrevista com uma única pessoa, seis (com um a 10 entrevistados) e três (com 16 a 27 entrevistados). Em relação aos nove artigos que utilizaram questionário como fonte de coleta em seis a amostra foi de até 50 pessoas, dois (até 102 pessoas) e um (com 894 pessoas). Os demais artigos ou eram ensaios ou recorreram a documentos e bibliografias para a coleta dos dados.

Com base nas leituras, pode-se inferir que o pilar ambiental ainda tem predominância nos estudos, seguido do pilar social e econômico, esse último parece estar sendo um pouco negligenciado no contexto das compras públicas sustentáveis. No entanto, ainda existem muitas divergências sobre os conceitos da sustentabilidade (MILLAR; GITSHAM, 2013). Por essa razão, muitas vezes é dado mais ênfase às questões ambientais, embora o equilíbrio entre os três pilares do TBL seja primordial.

Em relação ao ambiente de pesquisa ou unidade de análise, dos 39 artigos analisados, 11 estudos foram aplicados em Universidades e Institutos Federais; nove em outros órgãos federais; cinco em órgãos estaduais, e em órgãos municipais; seis

R. gest. sust. ambient., Florianópolis, v. 10, n. 2, p. 2-24, jun. 2021. 
abordaram a alimentação escolar e a agricultura familiar; um abordou as micro e pequenas empresas e sete em outros órgãos ou abordagens gerais.

Após uma análise mais aprofundada nos 39 artigos, o Quadro 4 apresenta alguns apontamentos (feitos pelos autores dos artigos), com relação aos aspectos ligados à: legislação, ao processo, aspectos culturais e econômicos que podem representar obstáculos para a efetivação das compras públicas sustentáveis.

\section{Quadro 4 - Obstáculos para a efetivação das compras públicas sustentáveis}

\begin{tabular}{|c|c|c|}
\hline Aspectos & Apontamentos & Autores \\
\hline \multirow{4}{*}{$\begin{array}{l}\text { Normativos/ } \\
\text { legislação }\end{array}$} & $\begin{array}{l}\text { A Instrução Normativa (IN) n. 1/2010 privilegia os critérios de caráter } \\
\text { ambiental em detrimento dos aspectos sociais; as especificações } \\
\text { dos produtos constantes no Catmat possuem um papel relevante } \\
\text { para a implementação das licitações sustentáveis. }\end{array}$ & $\begin{array}{l}\text { Castro, Silva e } \\
\text { Lopes, } 2014 .\end{array}$ \\
\hline & $\begin{array}{l}\text { Não foi encontrada instituição pública oficial ou instituição } \\
\text { credenciada certificando as exigências contidas nos instrumentos } \\
\text { convocatórios, isso reforça a tendência do Brasil em regulamentar } \\
\text { as Licitações Sustentáveis. }\end{array}$ & $\begin{array}{l}\text { Castro et al., } \\
\quad 2013 .\end{array}$ \\
\hline & $\begin{array}{l}\text { A inserção de critérios de sustentabilidade nas aquisições de } \\
\text { produtos e serviços pode impactar em mudanças na cadeia } \\
\text { produtiva do setor empresarial. }\end{array}$ & $\begin{array}{l}\text { Mendonça et al., } \\
2017 .\end{array}$ \\
\hline & $\begin{array}{l}\text { Apesar das legislações sobre CPS e da constatação de grandes } \\
\text { benefícios para a sociedade em longo prazo, elas ainda estão } \\
\text { restritas a poucos órgãos públicos. }\end{array}$ & $\begin{array}{l}\text { Rosset e Finger, } \\
2017 .\end{array}$ \\
\hline \multirow[b]{3}{*}{ Processuais } & $\begin{array}{l}\text { A falta de informações sobre o processo licitatório, ainda é uma } \\
\text { barreira ou desafio e é necessária capacitação as MPEs. }\end{array}$ & $\begin{array}{l}\text { Do Amaral Motta } \\
\text { e Oliveira, } 2015 .\end{array}$ \\
\hline & $\begin{array}{l}\text { Induzir critérios sustentáveis para as licitações, além das normas, } \\
\text { requer capacitação dos administradores. }\end{array}$ & $\begin{array}{l}\text { Castro et al., } \\
2014 .\end{array}$ \\
\hline & $\begin{array}{l}\text { Algumas questões precisam ser aprimoradas, como a elaboração de } \\
\text { guias práticos, esquemas de rotulagem e certificação ambiental. }\end{array}$ & $\begin{array}{l}\text { Couto e Ribeiro, } \\
2016 .\end{array}$ \\
\hline \multirow{8}{*}{ Culturais } & $\begin{array}{l}\text { Aspectos culturais: Os avanços das CPS se limitam a questões } \\
\text { ambientais e a dimensão social. }\end{array}$ & $\begin{array}{l}\text { Oliveira } \\
\text { Santos, } 2015 .\end{array}$ \\
\hline & $\begin{array}{l}\text { Existência de conflitos na cadeia reversa em relação à distribuição } \\
\text { dos custos da coleta, a falta de soluções regionais para as atividades } \\
\text { de reciclagem; precária fiscalização; falta de incentivos tributários; } \\
\text { baixo interesse de fabricantes em modificar seus produtos. }\end{array}$ & $\begin{array}{l}\text { Demajorovic e } \\
\text { Sencovic, } 2015 .\end{array}$ \\
\hline & $\begin{array}{l}\text { Há barreiras envolvendo aspectos institucionais, tais como cultura } \\
\text { organizacional resistente a mudanças, ausência de capacitação etc. }\end{array}$ & $\begin{array}{l}\text { Couto e Ribeiro, } \\
2016 .\end{array}$ \\
\hline & $\begin{array}{l}\text { É importante observar o princípio do eco eficiência, necessidade dos } \\
\text { gestores a promoverem a conscientização sobre a utilização do } \\
\text { recurso de forma racional e eficaz. }\end{array}$ & Araújo, 2011 \\
\hline & $\begin{array}{l}\text { Os aspectos econômicos e ambientais são mais notáveis nos } \\
\text { critérios colocados nos processos que as questões sociais. }\end{array}$ & $\begin{array}{c}\text { Weber e } \\
\text { Machado, } 2016\end{array}$ \\
\hline & $\begin{array}{l}\text { A maioria das universidades busca adquirir produtos de qualidade, } \\
\text { com uma durabilidade maior e menor consumo de água e energia, } \\
\text { mas há pouca preocupação, por exemplo, da compra de carros } \\
\text { menos poluentes e produtos feitos com materiais reciclados. }\end{array}$ & Hall et al., 2014. \\
\hline & $\begin{array}{l}\text { No setor privado, a burocracia para se conseguir o apoio político } \\
\text { necessário para a mudança dos processos, ou até mesmo, a cultura } \\
\text { pouco acostumada com o novo sistema, pode dificultar a adoção de } \\
\text { práticas ambientalmente sustentáveis. }\end{array}$ & $\begin{array}{l}\text { Silva, A, } \\
\text { Bohnke e Silva } \\
\text { K., } 2016 .\end{array}$ \\
\hline & $\begin{array}{l}\text { "Aproximadamente } 47,4 \% \text { dos municípios brasileiros adquiriram } \\
\text { alimentos da agricultura familiar para a alimentação escolar, mas o } \\
\text { percentual de compras foi, em média de } 22,7 \% \text {, em } 2010 \text { ". A }\end{array}$ & $\begin{array}{l}\text { Saraiva et al., } \\
\quad 2013\end{array}$ \\
\hline
\end{tabular}

R. gest. sust. ambient., Florianópolis, v. 10, n. 2, p. 2-24, jun. 2021. 


\begin{tabular}{|l|l|c|}
\hline Econômicos & $\begin{array}{l}\text { inviabilidade de fornecimento regular e constante, além de outros } \\
\text { limites apresentados pelas EE, se destacou como justificativa para } \\
\text { o não atendimento dos } 30 \% \text {, especificados na legislação. }\end{array}$ & \\
\cline { 2 - 3 } & $\begin{array}{l}\text { As compras públicas têm grande impacto e influência econômica, } \\
\text { porque quando se faz uma licitação, o mercado se movimentar } \\
\text { absurdamente devido a grandeza da compra. Há necessidade de } \\
\text { programa de governo de apoio a compras públicas sustentáveis, que } \\
\text { seja elaborado em conjunto pelas áreas de planejamento, compras }\end{array}$ & 2012 \\
e meio ambiente e o Inmetro para definir os critérios de \\
sustentabilidade.
\end{tabular}

Fonte: elaborado pelos autores, a partir dos artigos analisados

Nos aspectos relacionados à legislação, observa-se a importância de os órgãos governamentais estabelecerem normativas para padronização dos critérios ambientais. Também carece da existência de órgãos/instituições credenciadas para a certificação, de forma a regulamentarem as compras públicas sustentáveis.

No que tange aos processos, percebe-se a falta de informações sobre o processo licitatório e que capacitações são necessárias para as micro e pequenas empresas compreenderem os esses fluxos. Sobre os aspectos culturais, percebe-se a resistência às mudanças e necessidade de conscientização sobre a utilização dos recursos de forma racional e eficaz.

Em relação aos aspectos econômicos, os fornecedores muitas vezes têm dificuldade de viabilizar um fornecimento regular e constante de produtos, como é o caso do fornecimento de insumos para a alimentação escolar. No entanto, dada a importância econômica das compras públicas, há necessidade de programa de governo de apoio a compras públicas sustentáveis (SILVA e BARKI, 2012). Acrescentamos que esses programas deveriam contemplar os três pilares da sustentabilidade abordados. Diante disso, nas considerações finais, apresentadas na seção 5 , alguns desses pontos serão retomados.

\section{CONSIDERAÇÕES FINAIS}

As compras públicas sustentáveis representam uma das importantes alternativas governamentais para a redução dos impactos ambientais. Por essa razão, o objetivo desse artigo foi analisar os avanços das pesquisas sobre compras públicas sustentáveis antes e depois da Conferência das Nações Unidas sobre Desenvolvimento Sustentável (Rio+20). Júnior; De Azeredo e Costa (2014) constataram uma evolução significativa das publicações sobre compras públicas sustentáveis a partir IN/SLTI/MPOG/2010 (BRASIL, MPOG, 2017). No entanto,

R. gest. sust. ambient., Florianópolis, v. 10, n. 2, p. 2-24, jun. 2021. 
apesar da evolução gradativa que houve na publicação de pesquisas no período de 2004 a 2015, Rosset e Finger (2017) apontam que ainda a produção nessa área é muito escassa.

Diante dos resultados constatados, há de se concordar com os autores, que houve uma evolução significativa das publicações até 2015. No entanto, em 2016 e 2017 houve uma queda considerável em relação aos anos anteriores e embora os estudos tenham sido significativos, ainda são insuficientes para dar conta de um assunto relevante como as compras públicas sustentáveis.

Diante das constatações apresentadas, a contribuição teórica dessa pesquisa está em evidenciar os avanços das pesquisas no contexto das compras públicas sustentáveis antes e após a Rio + 20 e também apontar alguns caminhos para que esse campo de estudo alcancem um avanço pleno. Embora as pesquisas a respeito das compras públicas sustentáveis tenham aumentado expressivamente após a Rio+20, elas estar perdendo a receptividade esperada no meio acadêmico.

Após analisarmos os dados, combinados a pequena quantidade de publicações do período estudado que nos forneceram argumentos para afirmar que o campo está em desenvolvimento. Por se tratar de assunto relevante para a área de gestão pública, carece de novas pesquisas e também que, pode estar sofrendo influências negativas das crises institucionais que vem acontecendo nos últimos anos no Brasil e em outros países que influenciam a economia brasileira, como é o caso dos EUA.

Conforme apontado por Rosset e Finger (2017), a temática sobre compras públicas sustentáveis tem evoluído em quantitativo de pesquisas nos últimos anos e deveria ser mais aprofundado cientificamente. Isso talvez esteja relacionado a ser esse tema novo que ainda carece de embasamento teórico de autores reconhecidos. Uma alternativa para aumentar a receptividades das pesquisas, seria embasar as compras públicas sustentáveis à luz de importantes teorias, tais como a Teoria Institucional, a Teoria Econômica, a Teoria dos Custos de Transação, Teoria dos Stakeholders, dentre outras. Assim esses estudos poderiam alcançar uma maior credibilidade, tanto no contexto nacional como internacional, uma vez que as preocupações com a sustentabilidade se estendem globalmente.

Os achados da pesquisa demonstraram que o campo está em desenvolvimento, mas sob o ponto de vista acadêmico ainda não atingiu a maturidade, pois importantes aspectos relacionados às compras públicas sustentáveis ainda têm

R. gest. sust. ambient., Florianópolis, v. 10, n. 2, p. 2-24, jun. 2021. 
sido negligenciados, visto a importância que essa temática representa no atual contexto global.

Como contribuições práticas e gerenciais, esse estudo apresentou alguns obstáculos para a efetivação das compras públicas sustentáveis que podem ser úteis aos órgãos governamentais e aos legisladores repensarem as estratégias e normativas, de forma a impulsionarem as compras públicas sustentáveis.

Com isso, apresentam-se algumas lacunas que podem ser objeto de pesquisas futuras: Porque os pilares sociais e econômicos estariam sendo negligenciados no contexto das pesquisas de compras públicas sustentáveis? As demandas sociais, tais como a inserção das micro e pequenas empresas e da agricultura familiar estariam sendo desconsideradas? Tendo em vista o montante gasto com compras governamentais, as empresas já se deram conta da oportunidade em venderem produtos sustentáveis para os governos? Os órgãos públicos são vistos pelas empresas como potenciais compradores? Essas inquietações poderiam motivar sugestões para estudos futuros.

\section{REFERÊNCIAS}

ARAÚJO, Maria Zenaide Farias de. Gestão universitária frente à inovação tecnológica: um enfoque no uso das compras públicas sustentáveis como instrumento de preservação ambiental. Eventos Pedagógicos, 2011, 2.3: 30-40. DOI: 10.30681/2236-3165.

BARDIN, Laurence. Análise de conteúdo. 4. ed. Lisboa: Edições 70, 2010.

BIDERMAN, R., BETIOL, L. MACEDO, L. MONZONI, M. MAZON R.(orgs) ICLEI (2008) Guia de compras públicas sustentáveis. Uso do poder de compra do governo para a promoção do desenvolvimento sustentável. 2. ed., Rio de Janeiro: Editora FGV, 2008.

https://doi.org/10.20435/intera\%C3\%A7\%C3\%B5es.v15i1.136.

BLACKBURN, Willian. The Sustainability Handbook: The Complete Management Guide to Achieving Social, Economic and Environmental Responsibility. 1st Edition.USA, Earthscan, 2007.

BRASIL, MPDG. [Site do Ministério do Planejamento, Desenvolvimento e Gestão, antigo MPOG]. Disponível em: <http://www.planejamento.gov.br/@@busca?SearchableText=compras>. Acesso: $17 / 7 / 2017$.

BRASIL, MPOG - Ministério do Planejamento, Orçamento e Gestão. Compras Públicas Sustentáveis em 2012. Disponível em:

R. gest. sust. ambient., Florianópolis, v. 10, n. 2, p. 2-24, jun. 2021. 
$<$ http://www.planejamento.gov.br/assuntos/logistica-e-tecnologia-dainformacao/noticias/compras-sustentaveis-tem-crescimento-de-219-no >.

Acesso: 07/7/2017.

BRASIL, Relatório da Conferência das Nações Unidas sobre o Meio Ambiente Humano. Estocolmo, 5-16 de junho de 1972 (United Nations Publication, No. E.73.II.A.14 e corrigendum), cap. I. Disponível em:<https://nacoesunidas.org/acao/meio-ambiente/>. Acesso: 30/11/2017.

BRASIL, Relatório da Conferência das Nações Unidas sobre o Meio Ambiente e Desenvolvimento. Rio de Janeiro, 3-14 de junho de 1992 (United Nations Publication, No. E.93.I.8 e corrigenda), I-III. Disponível em:<https://nacoesunidas.org/acao/meio-ambiente/>. Acesso: 30/11/2017.

BRASIL, Relatório da Conferência Internacional sobre Financiamento para o Desenvolvimento. Monterrey, México, 18-22 de março de 2002 (United Nations Publication, No. E.02.II.A.7), cap. I, resolução 1. Disponível em:<https://nacoesunidas.org/acao/meio-ambiente/>. Acesso: 30/11/2017.

BRASIL, Relatorio Rio+20: O Modelo Brasileiro. Relatório de sustentabilidade da organização da Conferência das Nações Unidas sobre Desenvolvimento Sustentável/Conferência das Nações Unidas sobre Desenvolvimento Sustentável. Organizador: Jose Solla. - Brasília: FUNAG, 2012. Disponível em: $<$ http://www.rio20.gov.br/documentos/relatorio-rio-20/1.-relatorio-rio-

20/at download/relatorio rio20.pdf>. Acesso: 20/10/2017.

BRASIL. Decreto no 7746/2012, 05 de junho de 2012. Contratações Públicas Sustentáveis. Diário Oficial da República Federativa do Brasil, Brasília, DF, 06 de junho de 2012. Disponível em: < https://www.planalto.gov.br/ccivil 03/ ato20112014/2012/decreto/d7746.htm>. Acesso: 20/5/2019.

CAMPAGNIN LUIZ, Lilian, et al. Inclusão de Práticas Ambientais nas Auditorias Realizadas no Âmbito de uma Instituição Federal de Educação. Revista de Gestão $\begin{array}{lllll}\text { Ambiental } & \text { e } & \text { Sustentabilidade, } & \text { DOI: }\end{array}$ https://doi.org/10.5585/geas.v3i2.102.

CASTRO, Jessica Kopak, et al. Licitações públicas sustentáveis: Um estudo em um ministério do Brasil. Revista Ambiente Contábil, 2013, 5.2: 86. Disponível em: < https://periodicos.ufrn.br/ambiente/article/view/4146>. Acesso: 20/4/2019.

CASTRO, Jessica Kopak, et al. Licitações Sustentáveis: Um Estudo em Instituições Federais de Ensino Superior na Região Sul do Brasil. Revista Metropolitana de Sustentabilidade, $\quad 2014, \quad 4.1$ : $31 . \quad$ Disponível em:< https://revistaseletronicas.fmu.br/index.php/rms/article/view/296>. Acesso: 20/5/2019.

CASTRO, Maria Alice Cruz; DA SILVA, Edson Vicente; LOPES, Ana Maria D.'Ávila. Contratações sustentáveis na administração pública brasileira: a experiência do Poder Executivo federal. Revista de Administração Pública-RAP, 2014, DOI: 48.1: 207235. http://dx.doi.org/10.1590/S0034-76122014000100009. 
COUTO, Hugo Leonnardo Gomides; COELHO, Cristiano. Fatores críticos no comportamento do gestor público responsável por compras sustentáveis: diferenças entre consumo individual e organizacional. Revista de Administração Pública-RAP, 2015, 49.2. Disponível em: https://www.scielo.br/j/rap/a/94ScGWkPFxPjGVbLWHszVGz/?lang=pt. Acesso: 20/5/2019.

COUTO, Hugo Leonnardo Gomides; RIBEIRO, Francis Lee. Objetivos e desafios da política de compras públicas sustentáveis no Brasil: a opinião dos especialistas. Revista de Administração Pública, 2016, 50.2: 331-343. Disponível em: < https://www.scielo.br/j/rap/a/X5M39ysNDHK4Bw7rRY4SL7S/?lang=pt>. Acesso: $24 / 5 / 2021$.

DA SILVA, Alessandra Kátia; BOHNKE, Hevilyn Shayeny; DA SILVA, Kerisson Dreann Neres Soares. Considerações acerca do processo de compras verdes aplicadas às empresas públicas e privadas. Refas-Revista Fatec Zona Sul, 2016, v. 2, n. 2, p. 21 41. DOI: http://dx.doi.org/10.26853/Refas ISSN-2359-182X v02n02 05.

DE SOUZA, Paula; PFITSCHER, Elisete Dahmer. Gestão e sustentabilidade ambiental: estudo em um órgão público do estado de Santa Catarina. Revista de $\begin{array}{llllll}\text { Contabilidade } \& \quad \text { Controladoria, } & \text { 2013, } & \text { 5.3: }\end{array}$ http://dx.doi.org/10.5380/rcc.v5i3.30134.

DO AMARAL MOTTA, Helaine; DE OLIVEIRA, Lilian Firme Pittou. Compras e Contratações Públicas Federais Sustentáveis: desafios na participação de micro e pequenas empresas do município de São Mateus/ES. Revista da Universidade Vale do Rio Verde, 2015, 13.2: 203-215. DOI: http://dx.doi.org/10.5892/ruvrd.v13i2.2269.

ELKINGTON, John, et al. Triple bottom line revolution: reporting for the third millennium. Australian CPA, 1999, 69.11: 75-76.

ELKINGTON, John. A Teoria dos Três Pilares. In: ELKINGTON, John. Canibais com garfo e faca. São Paulo: Makron Books, 2001.

GIL, Antonio Carlos. Como elaborar projetos de pesquisa. 4. ed. São Paulo: Atlas, 2008.

GOMIDES DO COUTO, Hugo Leonnardo; COELHO, Cristiano. Fatores críticos no comportamento do gestor público responsável por compras sustentáveis: diferenças entre consumo individual e organizacional. Revista de Administração Pública-RAP, 2015, 49.2. Disponível em:< https://www.scielo.br/j/rap/a/94ScGWkPFxPjGVbLWHszVGz/?lang=pt>. Acesso: 24/5/2021.

HALL, Rosemar José, et al. Compras Públicas Sustentáveis: Um Estudo Nas Universidades Federais Brasileiras. Amazônia, Organizações e Sustentabilidade, 2014, 3.1. DOI: http://dx.doi.org/10.17800/aos.v3i1.88.

HANSMANN, Ralph; MIEG, Harald A.; FRISCHKNECHT, Peter. Principal sustainability components: empirical analysis of synergies between the three pillars of

R. gest. sust. ambient., Florianópolis, v. 10, n. 2, p. 2-24, jun. 2021. 
sustainability. International Journal of Sustainable Development\& World Ecology, 2012, 19.5: 451-459. DOI: https://doi.org/10.1080/13504509.2012.696220.

IBGE - Instituto Brasileiro de Geografia e Estatística. PIB 2016. Disponível: <http:// http://seriesestatisticas.ibge.gov.br/series.aspx?vcodigo=ST12>. Acesso: 07/7/2017.

JÚNIOR, Milton Erthal; DE AZEREDO, Fabricia Santos Gomes; COSTA, Helder Gomes. Compras Públicas Sustentáveis: Um Mapeamento da Produção científica através da Bibliometria. Revista Científica Linkania, 2014. Disponível em: < https://scholar.google.com/scholar?hl=pt-

BR\&as sdt=0\%2C5\&q=Compras+P\%C3\%BAblicas+Sustent $\%$ C3\%A1veis $\% 3 A+U m$ +Mapeamento+da+Produ\%C3\%A7\%C3\%A3o+cient\%C3\%ADfica+atrav\%C3\%A9s+ da+Bibliometria\&btnG=> Acesso: 20/5/2021.

LAVOR, Anna Ariane Araújo; TURATTI, Luciana. Contratações Públicas Sustentáveis no Brasil. Revista Gestão \& Sustentabilidade Ambiental, 2018, v. 7, n. 2, p. 335354. DOI: http://dx.doi.org/10.19177/rgsa.v7e22018335-354.

LUIZ, Lilian Campagnin et al. Inclusão de práticas ambientais nas auditorias realizadas no âmbito de uma instituição federal de educação. Revista de Gestão Ambiental e Sustentabilidade, 2014, v. 3, n. 2, p. 92-112. Disponível em:< https://periodicos.uninove.br/geas/article/viewFile/9873/4575>. Acesso: 24/5/2019.

MACIAS-CHAPULA, Cesar A. O papel da informetria e da cienciometria e sua perspectiva nacional e internacional. Revista Ciência da informação, Brasília, 1998, v. $27, \quad$ n. 2, p. 134-140, maio/ago. Disponível em: < https://www.scielo.br/j/ci/a/rz3RTKWZpCxVB865BQRvtmh/?lang=pt> Acesso: 20/5/2021.

MENDONÇA, Ricardo Almeida Marques, et al. Institucionalização de Compras Públicas Sustentáveis: Uma Análise da Experiência do Governo de Minas Gerais. REAd-Revista Eletrônica de Administração, 2017, 23.3: 62-91. DOI: https://doi.org/10.1590/1413-2311.161.61307.

MILLAR, Carla CJM; GITSHAM, Matthew. The role of management development in achieving a culture change towards sustainability in the organisation. Journal of Management Development, 2013. Vol. 32 Issue: 3. DOI: https://doi.org/10.1108/jmd.2013.02632caa.001.

MINAYO, M.C.S. O desafio do conhecimento: pesquisa qualitativa em saúde. São Paulo, Hucitec, 2007.

NONATO, Raquel Sobral. Compras públicas sustentáveis no Brasil: análise da produção e circulação das ideias a partir da ressignificação dos atores. Dissertação (CMAPG) - Escola de Administração de Empresas de São Paulo, 2015. Acesso: $<$ http://bibliotecadigital.fgv.br/dspace/handle/10438/13603>. Disponível em: 30/11/2017.

OLIVEIRA, Bernardo Carlos SCM de; SANTOS, Luis Miguel Luzio dos. Public procurement as a policy for sustainable development. Revista de Administração Pública, 2015, 49.1: 189-206. DOI: http://dx.doi.org/10.1590/0034-76121833.

R. gest. sust. ambient., Florianópolis, v. 10, n. 2, p. 2-24, jun. 2021. 
ONU. [Site da Organização das Nações Unidas]. Disponível em: <https://nacoesunidas.org/docs/meio-ambiente/>Acesso: 29/10/2017.

RODRIGUES, Ana Beatriz et al. O Desenvolvimento da Ecoeconomia Aliada Ao Marketing Ambiental. Revista Gestão \& Sustentabilidade Ambiental, v. 7, n. 4, p. 452-475, 2018. DOI: 10.19177/rgsa.v7e42018452-475.

ROSSET, Andrea Cecília Soares; FINGER, Andrew Beheregarai. Compras públicas sustentáveis: uma revisão sistemática da pesquisa brasileira. Revista de Administração, Contabilidade e Economia da Fundace, v. 7, n. 3, 2017. Disponível em:< $\quad$ https://www.fundace.org.br/revistaracef/index.php/racef/article/view/412>. Acesso: 24/5/2019.

SANTOS, Fernanda dos et al. Avaliação da inserção de alimentos orgânicos provenientes da agricultura familiar na alimentação escolar, em municípios dos territórios rurais do Rio Grande do Sul, Brasil. Ciência \& Saúde Coletiva, 2014, v. 19, p. 1429-1436. Disponível em:< https://www.scielosp.org/article/csc/2014.v19n5/14291436/>. Acesso: 24/5/2021.

SANTOS, Jaqueline Guimarães; CÂNDIDO, Gesinaldo Ataíde. Sustentabilidade e participação social cooperativa de agricultores familiares no agreste da Paraíba/Sustainability and social participation cooperative family farmers in the arid zone of Paraíba. Revista Metropolitana de Sustentabilidade (ISSN 2318-3233), 2014, v. 4, n. 2, p. 47-63. Disponível em:< https://revistaseletronicas.fmu.br/index.php/rms/article/view/278>. Acesso: 24/5/2021.

SARAIVA, Elisa, et al. Panorama da compra de alimentos da agricultura familiar para - Programa Nacional de Alimentação Escolar. Revista Ciência \&Saúde Coletiva, 2013, 18.4. Disponível em: < https://www.scielo.br/j/csc/a/vhD3rprLbpKQyFmsHBfpDsJ/?lang=pt>. $\quad$ Acesso: 15/5/2019.

SENCOVICI, Luis Alfredo; DEMAJOROVIC, Jacques. Entraves e Perspectivas para a Logística Reversa do óleo lubrificante e suas embalagens. Revista de Gestão Ambiental e Sustentabilidade: GeAS, 2015, v. 4, n. 2, p. 83-101. Disponível em:< https://dialnet.unirioja.es/servlet/articulo?codigo=5198754>. Acesso: 24/5/2019.

SILVA, Renato Cader da; BARKI, Teresa Villac Pinheiro. Compras públicas compartilhadas: a prática das licitações sustentáveis. Revista do Serviço Público RSP, 2012, v. 63, n. 2, p. 157-175. Disponível em: <http://repositorio.enap.gov.br/handle/1/1817>. Acesso: 24/5/2019

SOUSA, Anete Araújo de et al. Cardápios e sustentabilidade: ensaio sobre as diretrizes do Programa Nacional de Alimentação Escolar. Revista de Nutrição, 2015, v. 28, n. 2, p. 217-229. Disponível em:< https://www.scielo.br/j/rn/a/fVf9T4PkZvZztSnd75zyZKK/?lang=pt>. $\quad$ Acesso: 20/5/2019.

WEBER, Josiane; MACHADO, Nelson Santos. Sustainable Public Biddings: The Case Of Universidade Federal da Fronteira Sul's University Restaurant. RACE-Revista De

R. gest. sust. ambient., Florianópolis, v. 10, n. 2, p. 2-24, jun. 2021. 
Administração, Contabilidade E Economia, 2016, v. 15, n. 2, p. 419-446. DOI: https://doi.org/10.18593/race.v15i2.10272.

R. gest. sust. ambient., Florianópolis, v. 10, n. 2, p. 2-24, jun. 2021. 